\title{
Impact of Interactivity in Virtual Brand Communities on Consumer Behaviors Taking Mi Community as an example
}

\author{
Hongwei $\mathrm{Li}^{1}$ \\ ${ }^{1}$ School of Economics and Management, Beijing Jiaotong University, Beijing, China
}

\begin{abstract}
The development of mobile Internet technology makes people break away from the time and space restrictions, and enables them to interact with each other who bought the same brand as they do or who will buy products or services of a brand through the online virtual brand community. Mi Community is taken as an example in this study. The theories of the virtual brand community, interactivity in the community and consumer behavior are introduced, and a theoretical model that reflects the impact of interactivity in virtual brand communities on consumer behavior is built to illustrate the process of interactivity in communities promoting consumer behavior.
\end{abstract}

\section{Introduction}

According to the 45 th report released by the China Internet Network Information Center in 2020, by March 2020, the number of Internet users in China has reached 904 million, and the Internet availability rate has reached $64.5 \%$; the number of mobile Internet users has reached 897 million, and $99.3 \%$ of Internet users surf the Internet using mobile phones, much higher than the proportion of Internet access using TVs, desktop computers, notebooks and tablets. China has had 710 million online shopping users up to now, accounting for $78.6 \%$ of the total number of Internet users. The number of people shopping online using mobile phones has reached 707 million, accounting for $78.9 \%$ of the mobile Internet users [1].

The popularity of mobile Internet and mobile shopping has provided a technical foundation for the emergence of Internet-based social commerce. The user-centric network platform, especially WeChat, Weibo, etc., focuses on the interaction, sharing, and communication between users, which fits with the trend of sharing, fission, and communication of goods in social commerce, thus realizing the perfect combination of shopping and social contact, and resulting in the explosive growth of social commerce. Consequently, many traditional brand communities began to integrate with virtual network platforms, formed a large number of virtual brand communities. Compared with traditional e-commerce, the social commerce based on virtual brand communities is developing into an effective marketing medium for maintaining the relationship between enterprises and consumers. Thus, the study of customer behavior in virtual communities not only can provide theoretical guidance for network marketing of enterprises, and reduce the cost of acquiring customers, but also help enterprises formulate targeted marketing strategies.

\section{Related Theories}

\subsection{Virtual brand community}

Virtual brand community is "a special form of the combination of virtual community and brand community [2]. The concept of brand community was first proposed by Muniz and O'Guinn. McAlexander \& Schouten held that the participants of a brand community are those who have owned the products of this brand [3]. Wellman pointed out that the scope of the virtual brand community is not subject to geographic restrictions. From the perspective of enterprises, Srinivasan and Verona \& Prandelli highly affirmed the importance of the virtual brand community in developing customer loyalty [4]. Algesheimer proposed a network-enhanced brand community, believing that online communities, especially virtual communities formed by brand enthusiasts, are also a form of brand community [5]. It is widely believed by scholars such as Kozinets that the virtual brand community is a pattern of manifestation of the traditional physical brand community in the cyberspace [6]. In summary, this study proposes that the virtual brand community is a brand community in which members communicate with each other with the Internet as a medium. The communication and interaction in communities are realized through the Internet, and members of the community form a social relationship in this process.

\subsection{Interactivity}

Interaction is a key characteristic of the virtual brand 
community, and the basis for the formation of social relations. The interaction in the virtual brand community is an activity in which members of the community communicate about the brand and make corresponding feedback using the Internet as a medium [7]. It is also the process of members constantly perceiving and creating value. The interaction of members in the virtual brand community is divided into online interaction and offline interaction. Online interactions include the exchange of information about the brand between members in the virtual community. Offline interactions include some exchange activities spontaneously organized by community members or enterprises. For example, enterprises organize some community members to experience brand products offline and exchange their experiences with other members in the community. The interaction happens not only among consumers, but also between consumers and enterprises, brands and products [8].

The degree of participation of members of the virtual brand community is a key factor for the evaluation of interactivity, which can be reflected in the frequency of interaction, the degree of interaction, and the contents of interaction [9]. The frequency of interaction means the number of times of interactions made by community members. The more actively members participate in interaction, the more active they are. The degree of interaction means the intensity and depth of communication among members, including low-level information exchange and deep emotional interaction. The contents of interaction mean the level of information quality, i.e., the validity and accuracy of information obtained by members. There are three main purposes for members to participate in the interaction. First, it is to obtain information of products or services. Second, it is to establish social connections with other members of society, gain vanity, and engage in affective interaction. Third, it is for entertainment. Thus, three perceived values are produced among members through interaction in the community: functional value, social value and entertainment value [10]. Consumers gradually identify with the community, and develop trust in the brand through the continual obtainment of perceived value from the community, while trust is the prerequisite for consumer behavior.

\subsection{Consumer behavior}

Consumer behavior means the sum of psychological and realistic expressions of consumers in demand psychology, purchase motivation, consumption intention, etc., and the most important behavioral expression is the purchasing behavior. The purchasing decision-making process consists of several stages such as problem identification, information collection, scheme evaluation, purchase decision and post-purchase behavior. In the stage of problem identification, needs are identified and linked to specific products or services. In the stage of information collection, product or service information is obtained from multiple sources to improve the decision-making rationality. In the stage of scheme evaluation, various purchase schemes are formed according to the combination of attributes, benefits and values of products or services, and the purchase attitude is confirmed. In the stage of purchase decision, purchasing intentions and preferences are formed between different schemes. In the stage of post-purchase behavior, the value obtained by the purchase is evaluated, and satisfaction or dissatisfaction is expressed through actions or intention to recommend products or services to others. In this study, two behaviors are extracted from the entire purchasing decision-making process as indicators to evaluate consumer behaviors, namely purchase behavior and post-purchase behavior [11].

Different types of virtual communities have different functions and purposes, as well as different levels of participation of members. When studying virtual communities of consumption type, Kozinets divides consumers into browsers, enthusiasts, compounders and community members according to the relationship between consumers and consumer behavior (low/high) and the relationship between consumers and virtual community (weak/strong) [12], as shown in Table 1.

Table1. Types of Consumers in the Virtual Community

\begin{tabular}{|l|l|l|l|}
\hline $\begin{array}{l}\text { Consumer } \\
\text { behavior } \\
\text { relationship }\end{array}$ & High & Enthusiasts & $\begin{array}{l}\text { Community } \\
\text { members }\end{array}$ \\
\cline { 2 - 4 } & Low & Browsers & Compounders \\
\cline { 2 - 4 } & & Weak & Strong \\
\cline { 2 - 4 } & & Virtual community relationships \\
\hline
\end{tabular}

The browsers have a weak tie with the virtual community. They have a low sense of belonging to the virtual community, lack contact with the community, and have a short-time interest in community consumer behaviors. The common points of enthusiasts and browsers lie in the lack of special relationship with and the low sense of belonging to the virtual community. However, enthusiasts maintain a high level of enthusiasm for the consumer behavior of the virtual community. Compounders are exactly opposite to enthusiasts. Compounders interact more frequently with the virtual community and keep a close connection with the community, but they are not showing much enthusiasm for the consumer behavior of the community. Community members not only interact frequently with the community, but also keep a high interest in the consumer behavior of the virtual community.

After purchasing products or services, consumers can experience the entire purchasing process and the products or services themselves. The process of members evaluating their own consumer experience and sharing it in the community is the process that they interact with other community members. Other members can get more information about products or services by browsing these comments or communicating with the sharer. In this process, the sharer creates functional value. The sharers can also obtain approval from others, respond to messages, or establish social relationships with others from each 
sharing process. In this process, the sharer creates the social value or entertainment value. These values continue to make the community more prosperous and the information more reliable through the interactive behavior of the community members, thereby making the community members more attached to the community. Therefore, stimulate members of the community to produce more consumer behavior.

To sum up, a research model on the impact of interactivity on consumer behavior in the virtual brand community is built in this study, as shown in Figure 1.

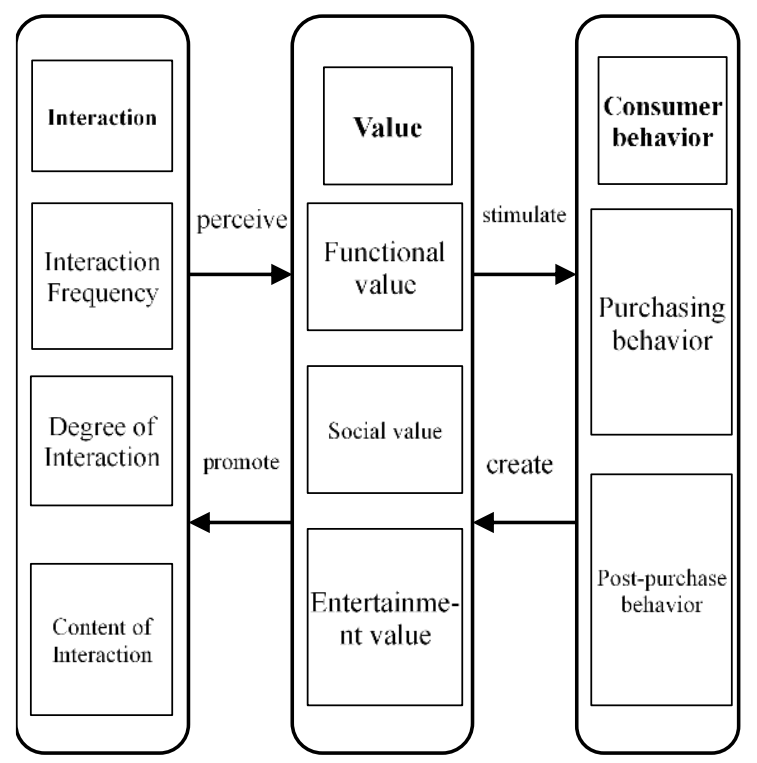

Fig1. Research Model of the Impact of Interactivity on Consumer Behavior in the Virtual Brand Community

\section{Mi Community members' interaction and consumption behavior}

\subsection{Introduction to Mi Community}

Founded on August 1, 2011, Mi Community is an online communication group established by the enterprise based on the brand of Xiaomi. The Mi Community is a typical virtual brand community, in which many Xiaomi enthusiasts communicate and interact with each other, forming intimate social relationships. Since the beginning, Xiaomi has transformed some users into followers. They develop from the initial Internet interactive products to the Xiaomi forum, and then to the Mi Community to attract followers. Xiaomi can't gain such a great success without the Mi Community and the continuous consumption of its followers.

\subsection{Interaction of Mi Community members}

3.2.1 Interaction between members and the brand: When building the Mi Community, Xiaomi set up different columns, each of which has its dedicated consulting part. In the official forum of the Mi Community, the brand owners not only can publish real-time brandrelated news in the community in the official name, but also reply to related contents just in the name of users.
Users can also directly post or participate in planning online/offline activities of Xiaomi. Community members $\log$ in to the Mi Community through their Xiaomi user IDs. Xiaomi products that users are using are associated to their Xioami user IDs. As an access threshold for members of the community, Xiaomi user ID excludes people who have nothing to do with the brand. Thus the interaction and contents in the community are all related to the brand.

3.2.2 Interaction among members: The forms of interaction among community members often include posting, follow-up, and comment. In the Mi Community, the user's interactions are roughly about the use of brand products, self-experience, story sharing, photography, wallpaper, etc. Users receive rewards based on the number of likes. The posts of "activity topic" and "topic participation" with higher quality can attract more attention from community members. The continued increase in the frequency of interaction can also affect the user's degree of participation in it. The amount of replies and degree of participation in the follow-up posts under these posts with a high interaction degree determine the quality and resulting benefits of the posts. There are few meaningless expressions in these posts, and most of them are topic-related expressions.

3.2.3 Interaction between members and enterprises: In the virtual community of a brand, the enterprise and its members participate in interactions to create and share value. The community interaction must be accompanied by participation and communication. In the $\mathrm{Mi}$ Community, by playing the role of Xiaomi's product manager, brand word-of-mouth referrer, dream sponsor, etc., consumers enthusiastically involve in the details of Xiaomi's products, and participate in product research development, marketing and promotion to complete user services and experiences. Xiaomi not only maintains communication with users in the process of design, but also focuses on user feedback in sales and after-sales links. For example, Xiaomi's MIUI R\&D personnel interact with consumers on the forum, and integrates the development version every Friday, so that users can upgrade the experience, and vote on the MIUI forum to generate a user experience report.

\subsection{Consumer behavior of community members}

According to the data on network services released in Xiaomi's annual report of 2019, the revenue from Internet services reached RMB 19.8 billion in 2019, with a yearon-year increase of $24.4 \%$. The monthly active users of MIUI reached 309.6 million, a year-on-year growth of $27.9 \%$, including 109.0 million of monthly active users of MIUI in mainland China. The monthly active users of Smart TV and Mi Box reached 27.7 million, increasing by $49.1 \%$ on year-on-year basis. By December 31, 2019, the number of paying users exceeded 3.7 million, growing by $62.9 \%$ year on year [13]. It can be seen that in the Mi Community, through interactions among members, brands, enterprises, and products and services, community members not only continue to purchase Xiaomi's products and services, but also share shopping experience and problems encountered with community members through 
the Mi Community.

\section{Conclusions}

Through participating in interactions, every member of the virtual brand community not only can perceive the value brought by the community, but also can create value through its own participation, thus perfecting the community function. Members deepen their identification with the brand and the community through continuous interactions, so that they would continue to purchase products and services of the brand, make timely feedback, and share the feedback in forms such as comments in the virtual brand community. Therefore, interactivity is the key to establishing and maintaining a virtual brand community, as well as a vital factor for promoting consumer behaviors. To sum up, enterprises should put more emphasis on how to make use of the interaction among virtual brand community members to guide consumers to produce consumer behaviors.

\section{ACKNOWLEDGMENT}

The authors would like to thank the two anonymous reviewers for their comments on earlier versions of the paper and for their insightful suggestions that have helped improve the final manuscript.

\section{REFERENCES}

1. The 45th China Statistical Report on Internet Development. Available at: http://www.cnnic.cn/hlwfzyj/hlwxzbg/hlwtjbg/20200 4/P020200428596599037028.pdf

2. MUNIZ A. M, JR O', GUINNTC. Brand Community [J]. Journal of Consumer Research,2001,27(4): 412432.

3. MCALEXANDER J H, SCHOUTEN J W, KOEING $\mathrm{H}$ F. Building brand community[J]. Journal of Marketing,2002,66(1): 38-54.

4. Chun Liu, Yali Wu. Research on the meaning, dimension and influencing factors of Virtual Brand Community interaction [J]. Commerce,2015(25):114115.

5. René Algesheimer, Andreas Herrmann, Marcus Dimpfel. Die Wirkung von Brand Communities auf die Markenloyalität - eine dynamische Analyse im Automobilmarkt. Zeitschrift für Betriebswirtschaft, 2006, Vol.76 (9), pp.933-958.

6. KOZINETS R V. The field behind the screen: Using netnography for marketing research in online communities [J]. Journal of Marketing Research, 2002 39(1), 61-72.

7. Yu Wang. Interactive research on Xiaomi Virtual Brand Community [D]. Jiangxi Normal University,2019.

8. Mengmeng $\mathrm{Xu}$. Research on the influence of virtual brand community interaction on brand loyalty -- a case study of Xiaomi [J]. Journal of Pingdingshan university,2016,31(02):104-109.

9. Xiangyang Ma, Yulong Wang, Bo Wang, Song Yang. Research on the Perception, Attitude and Participation Behavior of Virtual Brand Community members [J]. Management Review, 2017, 29 (07): 7081.

10. Lei Meng. Influence of virtual Brand Community perceived value on consumer Behavior [J]. Business Economics Research,2018(02):46-49.

11. Fanshi Kong, Huiping Wang. Research on the relationship between interpersonal interaction in virtual Communities and Online consumption Behavior $\quad[\mathrm{J}]$. China Collective Economy,2008(07):73-74.

12. KOZINETS R V. The field behind the screen: Using netnography for marketing research in online communities [J]. Journal of Marketing Research, 2002 39(1), 61-72.

13. Xiaomi Corporation's report of full-year performance for the year ending December 31, 2019. Available at: https://pdf.dfcfw.com/pdf/H2_AN202003311377291 938_1.pdf. 